a way that it is clear to everybody concerned, particularly the patients.

A. M. P. Kellam, University Hospital of Wales, Cardiff CF4 $4 X W$

\section{Psychotherapy training: brief therapies preferred}

Sir: The College guidelines on what constitutes a good training in psychological treatments are soon to be updated. The current guidelines (1986) are ambitious and large regional rotations have made it harder to organise training in longer psychotherapies. We conducted a brief survey of the 82 senior house officers and registrars in the Oxford region asking what training in psychological treatments had been received and what trainees thought was important. The response rate was $63 \%$.

We asked trainees to rank the importance for your psychiatric training' of training in various treatment modalities. (Higher scores mean greater perceived importance). Mean rankings were: cognitive behavioural therapy (CBT) 4.3, brief focal individual psychotherapy ('2-3 cases, $<3$ months/case') 4.0, counselling 2.4, marital therapy 2.3, individual dynamic psychotherapy ('>6 months/case') 2.0, cognitive analytical therapy 2.0, dynamic group therapy 1.1. The survey did not attempt further definition of these terms.

A trainee's ranking of CBT and individual dynamic psychotherapy did not significantly depend on whether he or she had had supervised training in these modalities, nor on total length of psychiatric training. Career psychiatrists were more likely to value highly training in brief focal individual psychotherapy than GP trainees, who preferred counselling. When the rankings from these two groups were combined. GP trainees and psychiatrists did not differ significantly $(P=0.2)$ in the relative importance they attached to these brief therapies $v$. individual dynamic psychotherapy; both thought the briefer therapies more important for training.

It may be difficult for SHOs and registrars to appreciate the relevance of longer term therapies when, at this stage in training, they routinely see patients for no more than six months. Alternatively, they may be sensitive to the focused way consultants work. Whatever is the correct explanation, it does seem that the College may place more emphasis than trainees on the value of training in longer individual dynamic psychotherapy: it would be interesting to know how far trainees have been consulted in drawing up the new guidelines.

ROYAL COLLEge OF PSYChIATRISTS (1986) Guidelines for training of general psychiatrist in psychotherapy. Psychiatric Bulletin, 10, 286-288.
R. H. MCShane and D. B. E. C. GILl, The Warneford Hospital, Headington, Oxford OX3 7JX

Sir: Drs McShane \& Dr Gill are to be commended on conducting a survey of 82 senior house officers and registrars. Their results support the importance of psychotherapy training as perceived by the trainees. It would be interesting to know how other items of psychiatric training would rate in comparison with the ratings for different forms of psychotherapy training. It is difficult to interpret the significance of their results and it may be hard for people at the beginning of training to see the relevance of longer term therapies.

The aim of the new College guidelines for psychotherapy training as part of general professional psychiatric training (Grant et al, 1993), in suggesting experience of longer term therapy, is to enable the trainee to understand complex aspects of this work, rather than to prepare the trainee fully to practise it. Experience of longer term therapy allows complex issues in a transference/counter-transference relationship to be explored and this is an important learning experience. These principles are often of importance in clinical management in psychiatry. Of course such experience will often be more difflcult and testing for a registrar or SHO than brief therapy, as it requires examination of personal feelings and attitudes in relation to the patient. It will be much more testing of the quality of teaching and supervision offered for psychotherapy which, if adequate, leaves the trainee with a difficult experience. The new guidelines are ambitious, but psychiatry should move towards a situation where all trainees are familiar with a wide range of psychotherapies, including more intensive approaches, and are able to apply psychotherapy principles to psychiatric practice. Otherwise we will be planning for a future psychiatric profession with a limited range of therapeutic skills. There is increasing demand from patient's organisations for psychiatrists to offer a wide range of talking treatments.

The guidelines were prepared in discussion with trainees who, on the whole, have welcomed these changes, as many wish to see the improvement in the quality of their training. Naturally they expressed anxiety about the additional demands made on their time and the requirement of the completion of a log book system.

Our present general professional training in psychotherapy compares unfavourably with other countries which have a much higher number of psychiatrists, such as the USA. Canada. Australia and New Zealand, each with roughly four times as many psychiatrists per 100,000 population. The demand for psychiatrists may be linked to their capacity to provide personal therapeutic work with patients. The psychiatrist in 
these countries is seen as expert in psychotherapy and in the application of psychotherapeutic principles to psychiatry. This is the way that the profession in this country needs to move if it is not to encourage the devolution of skilled clinical therapeutic practice to other professions.

Grant, S., Holmes, J. \& Watson, J. (1993) Guidelines for psychotherapy training as part of general professional psychiatric training. Psychiatric Bulletin, 17, 695-698.

N. O. T. TEmple, Chairman, Psychotherapy Section, Royal College of Psychiatrists

\section{An indictment of British psychiatry}

Sir: I have just attended a one-day workshop on post traumatic stress disorder, held at the College. The subject of treatment was left until the final hour, when two young research psychologists described a controlled trial they were to undertake. Mine was the only voice in a hall full of consultant psychiatrists expressing an interest in outcomes and the use of brief, effective psychodynamic/behavioural techniques. This void was a frightening indictment of British psychiatry.

Psychiatrists seem to be involving themselves less and less with individual therapy. Team management, committee attendance, assessments and reports are not enough. The consultant should be leading the therapeutic effort, able personally to take on challenging patients. If consultants continue to lead from behind, in a changing world, they may be left behind.

A. SANDERSON, South Bedfordshire Community Health Care Trust, Crombie House, 36 Hockcliffe Street, Leighton Buzzard, LU7 $8 \mathrm{HE}$

\section{Advertisement for part-time posts}

Sir: Could I draw colleagues' attention to the 'Part-Time' section of the British Medical journal classified advertisements? I learnt of this section by chance at an advisory appointments committee and realised that some advertisements may not appear under their speciality heading because they have only been placed in the PartTime section. As an example, in the 13 November 1993 Journal, 13 posts were advertised in the Part-Time section but I could find reference to only five of them in the respective specialty section. I wonder how widely known this practice is and whether it has narrowed the field of applicants for posts.

PETER REDER, Child \& Family Consultation Centre, Wolverton Gardens, London W6 7DQ

\section{Examination blues}

Sir: On receipt of a letter from the College last June, informing me I had failed the second part of the membership exam, I could not fail to notice that the letter was stamped with the 'Defeat Depression' - and the campaign logo. It is reassuring to see the College fostering a healthy sense of humour.

R. A. Laugharne, Princess Alexandra Hospital, Harlow, Essex CM2O 1QX 